\title{
Decentralized substations for low-temperature district heating with no Legionella risk,
} and low return temperatures

\author{
Yang, Xiaochen; Li, Hongwei; Svendsen, Svend
}

Published in:

Energy

Link to article, DOI:

10.1016/j.energy.2015.12.073

Publication date:

2016

Document Version

Peer reviewed version

Link back to DTU Orbit

Citation (APA):

Yang, X., Li, H., \& Svendsen, S. (2016). Decentralized substations for low-temperature district heating with no Legionella risk, and low return temperatures. Energy, 110, 65-74. https://doi.org/10.1016/j.energy.2015.12.073

\section{General rights}

Copyright and moral rights for the publications made accessible in the public portal are retained by the authors and/or other copyright owners and it is a condition of accessing publications that users recognise and abide by the legal requirements associated with these rights.

- Users may download and print one copy of any publication from the public portal for the purpose of private study or research.

- You may not further distribute the material or use it for any profit-making activity or commercial gain

- You may freely distribute the URL identifying the publication in the public portal 


\title{
Decentralized substations for low-temperature district heating with no Legionella risk, and low return temperatures
}

\author{
Xiaochen Yang ${ }^{1 *}$, Hongwei $\mathrm{Li}^{2}$ and Svend Svendsen ${ }^{3}$ \\ ${ }^{1,2,3}$ Civil Engineering Department, \\ Technical University of Denmark, Denmark \\ Building 118, Brovej \\ DK-2800 Kgs. Lyngby, Denmark \\ Email: xiay@byg.dtu.dk ${ }^{1 *}$, Tel: +45 52908567
}

\begin{abstract}
To improve energy efficiency and give more access to renewable energy sources, lowtemperature district heating (LTDH) is a promising concept to be realized in the future. However, concern about Legionella proliferation restricts applying low-temperature district heating in conventional systems with domestic hot water (DHW) circulation. In this study, a system with decentralized substations was analysed as a solution to this problem. Furthermore, a modification for the decentralized substation system were proposed in order to reduce the average return temperature. Models of conventional system with medium-temperature district heating, decentralized substation system with LTDH, and innovative decentralized substation system with LTDH were built based on the information of a case building. The annual distribution heat loss and the operating costs of the three scenarios were calculated and compared. From the results, realizing LTDH by the decentralized substation unit, $30 \%$ of the annual distribution heat loss inside the building can be saved compared to a conventional system with medium-temperature district heating. Replacing the bypass pipe with an in-line supply pipe and a heat pump, the innovative decentralized substation system can reduce distribution heat loss by $39 \%$ compared to the conventional system and by $12 \%$ compared to the normal decentralized substation system with bypass.
\end{abstract}

\section{Key words}

Low-temperature district heating; decentralized substation system; Legionella; distribution heat loss; return temperature; heat pump

\section{Highlights}

- A system of decentralized substations is a promising concept to realize lowtemperature district heating supply for multi-storey buildings without running the risk of Legionella. 
- Decentralized substations help reduce the distribution heat loss inside the building significantly compared to conventional system with domestic hot water circulation.

- A new concept that can reduce the return temperature for district heating is proposed and analysed.

\section{Introduction}

District heating is an efficient method of supplying heat to consumers in many regions, especially in high heat density areas. Compared with other heating systems, district heating is flexible in using various forms of energy, such as surplus heat from industrial processes, geothermal energy, solar energy, and also residual resources, which might be used increasingly in the future. Therefore, district heating can play an important role in realizing a system of sustainable energy with $100 \%$ renewable energy supply [1].

After long-term development, the current temperature level of most district heating systems is often below $100{ }^{\circ} \mathrm{C}$, but still high. To meet the lower heating demand of energy-efficient buildings in the future and give access to more low-temperature heat sources, the concept of $4^{\text {th }}$ Generation District Heating [1] has been proposed, with the aim of developing a district heating system with lower supply temperature. A recent study investigated the feasibility of supplying space heating with low-temperature district heating (LTDH) without compromising on comfort [2], which indicates that with 
extensive renovation and efficient heating equipment, LTDH supply is sufficient to provide an indoor temperature of $22^{\circ} \mathrm{C}$.

However, one obstacle to realizing LTDH is the conflict with hygiene requirements. Artificial aquatic systems are easily colonized with Legionella, which is the causative agent of Legionnaire's disease. Temperatures in water below $50^{\circ} \mathrm{C}$ and stagnancy are considered the main factors that promote the growth of Legionella. The common solution is to use a high-temperature regime and domestic hot water circulation. Most countries require the district heating supply temperature to be at least $60^{\circ} \mathrm{C}$ for large systems with circulation. Unfortunately, previous research has shown that the heat loss of a conventional system with domestic hot water circulation and a storage tank can be as much as $50 \%$ of all the energy delivered [3]. However, if the water volume can be limited, the proliferation of Legionella can be much restrained. According to the regulations of CEN/TR 16355 [4], a hot water system without a tank and circulation system has no need to be kept at a high temperature. So a system of decentralized substations can limit both the heat loss and the risk of Legionella. The domestic hot water can be produced in each apartment in a building using a compact flat-plate heat exchanger and distributed to the taps in the apartment with small-dimension pipes. In this way, the volume of the indoor domestic hot water system is so small that the risk of Legionella is eliminated without maintaining high temperatures. 
Some articles have presented investigations of the benefits of applying the decentralized substation system, but with medium-temperature district heating. Breuer and Loose [5] point out that decentralized supply of domestic hot water can save approximately $30 \%$ of heating energy consumption comparing to the conventional circulation system, making it an economically efficient alternative method for DHW production. Cholewa and Siuta-Olcha [6] conducted an practical measurement for a 4storey building with decentralized substations in Poland. By comparing the readouts of the heat provision and heat consumption (both space heating and DHW), they find the decentralized substation can achieve the efficiency of $67.1 \%$, and motivate the consumer to reduce their heat consumption by $19.2 \%$. In another article, Cholewa et al. [7] compare the measurements of a centralized heating system with gas boiler, a decentralized substations system with district heating, and a decentralized heating system with individual gas boiler for each dwelling. The decentralized substation system with district heating has $10.5 \%$ higher efficiency than the centralized system on annual average, but lower than the individual gas boiler system. However, more equipment for ventilation is required by the individual gas boiler system. Thorsen [8] provides a parametric study about the decentralized substation concept. According to the practical data, the investment of the decentralized substation system is on break-even level as the conventional system. And it can save $2-4 \mathrm{kWh} / \mathrm{m}^{2}$. yr energy without violating the comfort and hygiene requirements. 
In this study, we explored the feasibility and benefit of realizing LTDH by applying the decentralized substation unit. In addition, we proposed and investigated an innovative decentralized substation system with an in-line supply pipe and a heat pump, which aims to further reducing the return temperature. Three models were built up to simulate the scenarios of the conventional system supplied by $3^{\text {rd }}$ generation district heating, the decentralized substation system supplied by LTDH, and the innovative decentralized substation system supplied by LTDH respectively. The design information of the models was obtained from a case multi-storey building with decentralized substation system supplied by medium temperature district heating $\left(70^{\circ} \mathrm{C}\right)$. The model of decentralized substation system was compared with measurements of the case system to ensure accurate settings and parameter input, and is used to simulate the LTDH scenario by converting the supply temperature to $55^{\circ} \mathrm{C}$. The annual distribution heat loss, the resulting operation costs, the seasonal variation of the three scenarios, and the benefit of low return temperature were analysed and compared. The results provided by this study can be used to promote LTDH in the planning stage, and to improve the efficiency of the decentralized substation system.

\section{Materials and methods}

This section describes the methods for setting up the models that were made to investigate the energy performance of the heat distribution process. The distribution heat loss of three scenarios, as one crucial indicator of the efficiency for the heat distribution process, was simulated and compared. In this study, the distribution heat 
loss focused on is the heat loss from the building inlet to the apartment inlet.

Distribution heat loss inside the apartments and in the network was not taken into account. In addition, the economic performances of different systems related to the heat distribution process were analysed and compared. The investment costs were not included in this study, since the price of the equipment varies a lot among manufacturers. The benefit of a lower return temperature was also investigated from both energy and economy points of view. To make a common basis for the comparison, the conditions on the consumer side for three scenarios, such as heating demand, building insulation level, heating equipment, were all assumed to be the same.

\subsection{Information of the case system}

\subsubsection{Building information}

The case building is a six-floor residential building located in Denmark. The ground floor comprises two commercial stores. Each of the other floors has three apartments. The basement has a storage room and a technical room which only have space heating demand, while the rest of the basement is used for parking and is neither heated nor supplied with hot water.

The case building and the floor layout of the residential storeys are show in Figure 2.1. 


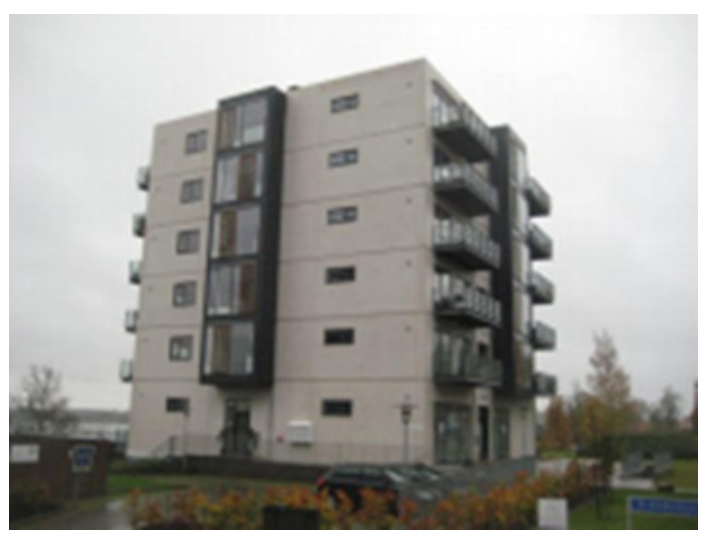

(a)

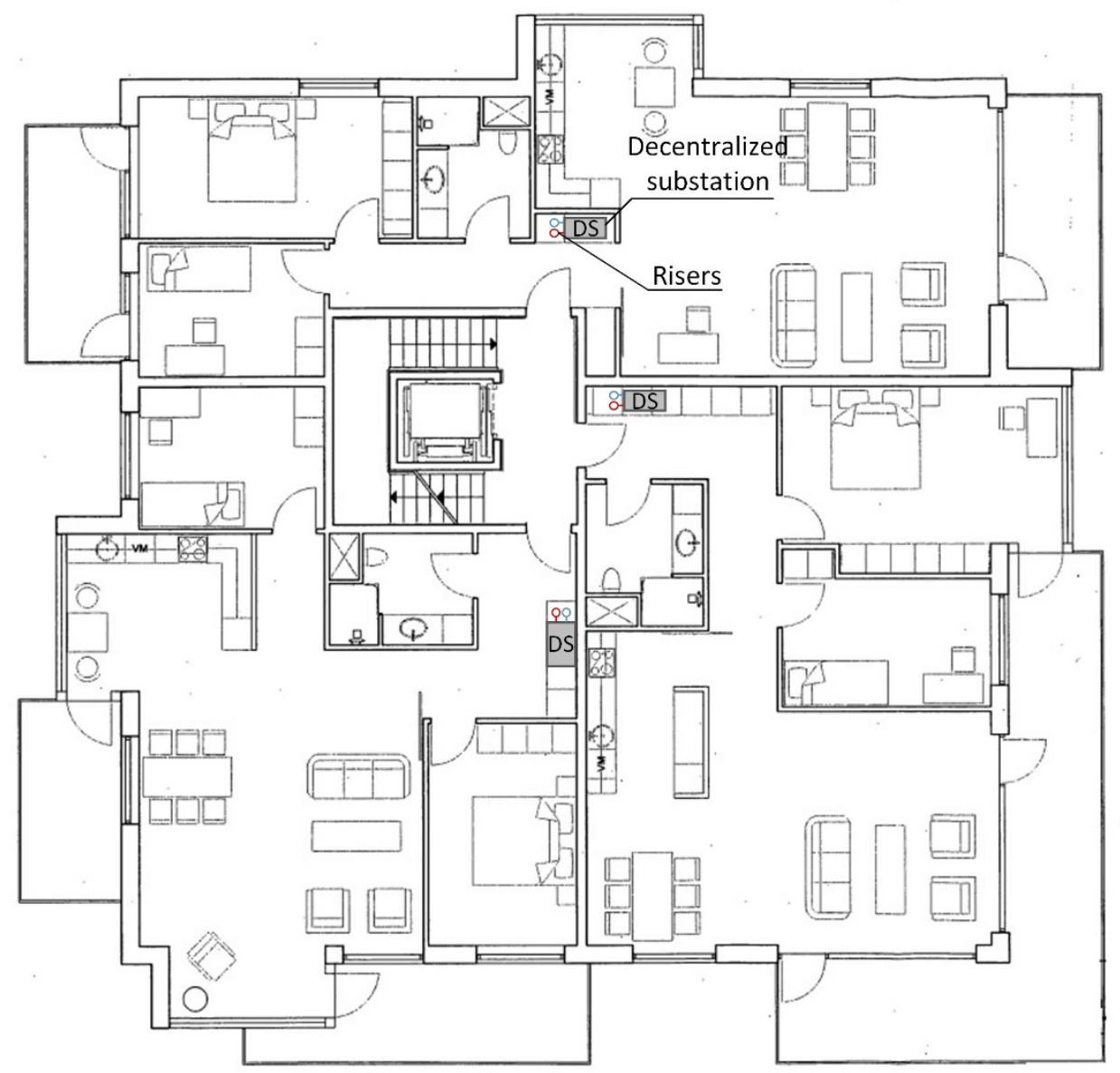

(b)

Figure 2.1 The reference building (a) and the floor layout (b) of the residential storeys

The apartment area is about $110 \mathrm{~m}^{2}$. As shown in Figure 2.1, each apartment has typical domestic hot water use with one kitchen, one shower head, and one hand basin. Floor 
heating in the bathroom is used all the year round for comfort. The building was constructed in 2006 and is well-insulated. The design space heating and domestic hot water demands are assumed to follow the Danish building code BR95[9], which requires the total energy supply should be less than $70 \mathrm{kWh} / \mathrm{m}^{2}$ per year plus $2200 \mathrm{kWh}$ divided by the heated floor area.

\subsubsection{Decentralized substation system in the case building}

The reference heat distribution system in the case building is the decentralized substation heating system, which is not very common in multi-storey residential buildings in Denmark. However, to promote the utilization of LTDH, the local district heating company decided to apply decentralized substation systems in some new residential buildings. Each flat in the case building has its own decentralized substation installed in the cabinet inside. The substation is connected with the district heating service supply and return pipes installed as risers in the cabinet. There are three risers in the building. The substations of the three flats on each floor are connected to different risers. The heat demand for both space heating and domestic hot water is supplied by the individual decentralized substations.

The type of substation unit used in the reference building is shown in Figure 2.2. 


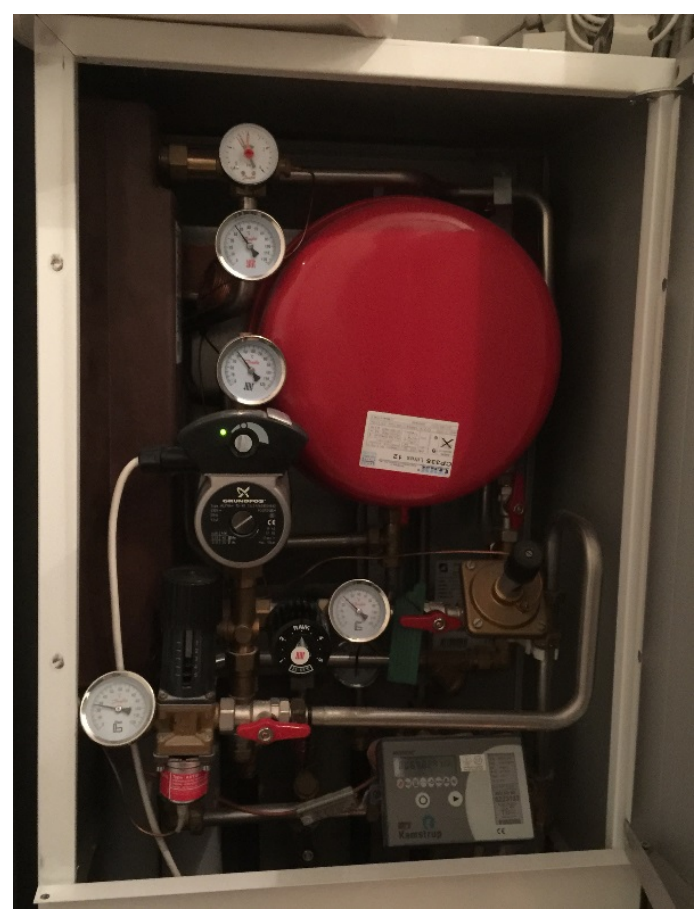

Figure 2.2 Decentralized substation unit

Figure 2.3 shows the installation and connection of the decentralized substation unit

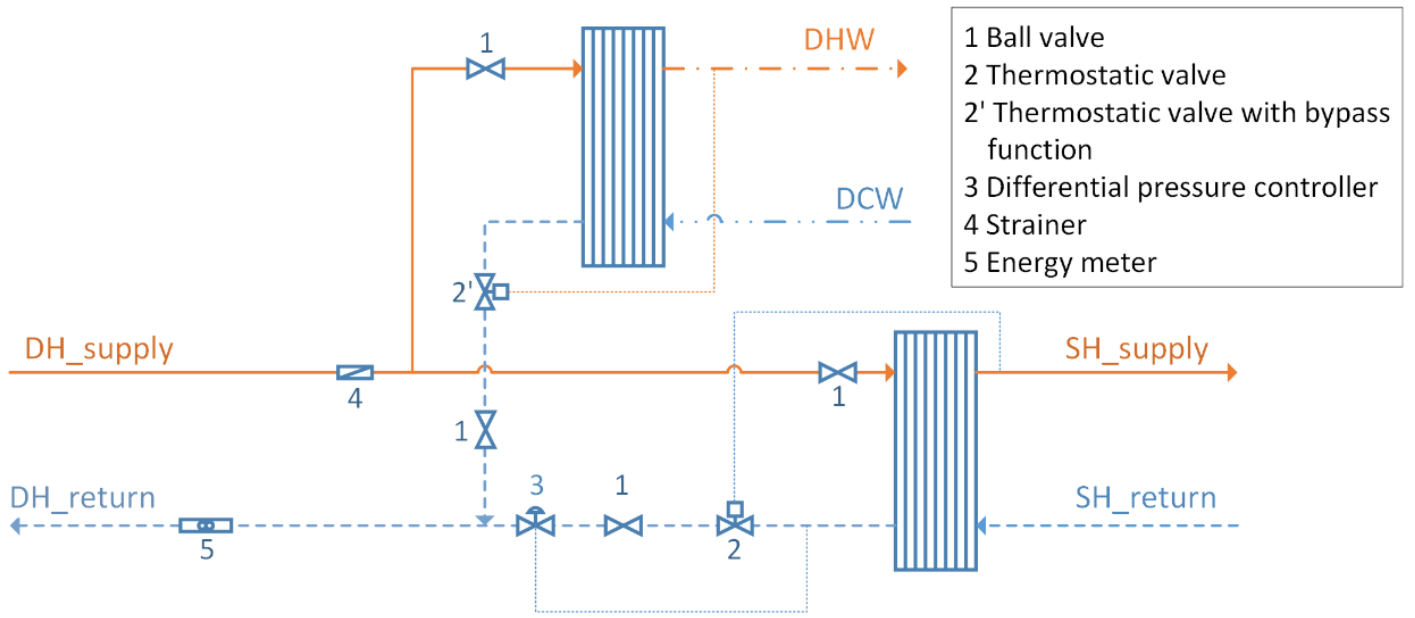

Figure 2.3 Connection of decentralized substation unit

The thermostatic valve $\left(2^{\prime}\right)$ of the domestic hot water heat exchanger also serves as a bypass to keep the supply line warm if necessary, so that an acceptable waiting time for domestic hot water can be guaranteed. Temperature and energy meters in the decentralized substation of each apartment record the accumulated heat consumption 
of the apartment. Normally, the time step of the meters was set to a daily or monthly basis. In this study, the meters were reset to save the data with a shorter time step $(0.5$ hr) for a two-day period for more accurate measurements. At the building inlet, an energy meter is installed to measure the overall heat supplied to the building from the district heating network and the district heating supply and return temperatures. The distribution heat loss of the case building was calculated as the subtraction between the measured total heat supply by the district heating network and the total heat consumption of the consumers. It was compared to the simulation results by the model. The measured return temperature was also compared to the calculated return temperature of the decentralized substation model.

\subsection{Distribution heat loss}

The distribution heat loss is an important factor in evaluating the energy-efficiency of a heating system, because it directly affects the overall energy supplied by the district heating. In this study, the distribution heat loss of the decentralized substation system includes the heat loss along the pipe, whereas in the conventional system with domestic hot water circulation, the heat loss of the storage tank also needs to be taken into account. The draw-off of domestic hot water can also affect the average return temperature, but since the draw-off happens only a few times a day and the draw-off periods are very short, the effect of domestic hot water draw-off on the average return temperature was ignored in this study. 
The basic principles for calculating the distribution heat loss from the pipes are illustrated by the following equation:

$$
Q_{H L}=\sum_{1}^{i}\left(\Phi_{i} \cdot l_{i} \cdot \Delta t_{i} \cdot \tau\right) / 1000
$$

where,

$Q_{H L}$ is the overall heat loss including all the pipe segments, [kWh]

$\tau$ is the integration time, for the heating season and non-heating season separately, [hr]

$\Phi_{i}$ is the heat loss coefficient of the $\mathrm{i}^{\text {th }}$ pipe segment, which depends on the pipe

dimensions and insulation level, $\left[\mathrm{W} / \mathrm{m} \cdot{ }^{\circ} \mathrm{C}\right]$

$l_{i}$ is the length of the $\mathrm{i}^{\text {th }}$ pipe segment, $[\mathrm{m}]$

$\Delta t_{i}$ is the temperature difference between the individual pipe and the ambient, $\left[{ }^{\circ} \mathrm{C}\right]$.

The pipe dimensions and insulation levels for the models were determined in accordance with Danish standards and regulations. In this study, the average pipe temperatures for the heating season and the non-heating season were different because of different operation methods. These lead to different distribution heat loss. They are defined in the following section.

\subsection{Investigations for the different scenarios}

In this section, the three scenarios for comparison are described. They were all designed to fulfil the same heat demand as the case building. All three systems were assumed to be applied in energy-efficient buildings with floor heating, where the LTDH supply is sufficient to provide comfort indoor temperature. The pipe dimensions were 
determined carefully following the corresponding design guidelines, and insulated to Class 4 according to the standard[10, 11]. Since all the risers were installed inside the cabinets in the flats, the surrounding ambient temperature for the distribution pipes was assumed to be $20^{\circ} \mathrm{C}$. The operation temperatures for each scenario were determined in accordance with Danish standards and regulations. To avoid Legionella, the temperature of the water in the circulation loop should be at minimum of $55^{\circ} \mathrm{C}$ and the tank should be kept at $60^{\circ} \mathrm{C}$. In terms of the system without circulation and heat storage, the water temperature should be no less than $45^{\circ} \mathrm{C}$ for comfort $[4,10]$. The heating season was defined as $1^{\text {st }}$ October to $31^{\text {st }}$ April in this study for seasonal analysis, which is applied for energy-efficient buildings in Denmark. The detailed assumptions and operations for the three models are illustrate in the following sections.

\subsubsection{Scenario 1. Conventional system with domestic hot water circulation}

Scenario 1 was built as the typical existing system for multi-family building with medium -temperature district heating. In such system, domestic hot water circulates at high temperature to avoid Legionella. Scenario 1 was used as reference case for the model comparison. A schematic of the conventional system is shown in Figure 2.4. 


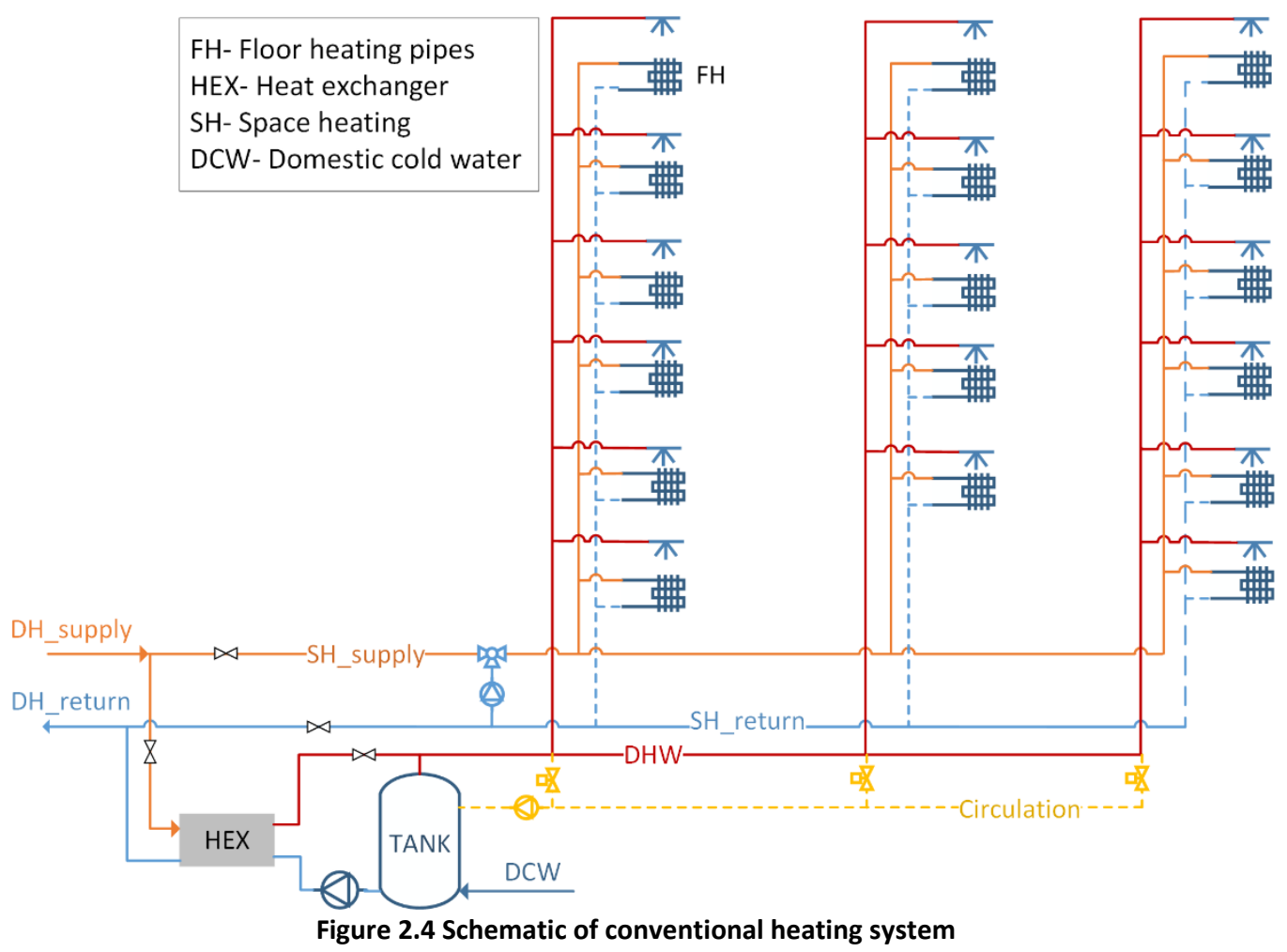

The conventional heating system has separate loops for space heating and domestic hot water. Space heating is supplied directly by the district heating network. In the study, the floor heating in the bathroom was still maintained during the non-heating season to provide comfort. The temperature of the space heating supply can be adjusted by mixing the return flow into the supply flow. A 3-way valve was used to regulate a proper mixed temperature for space heating supply. For domestic hot water, an in-line supply pipe was utilized to achieve high efficiency circulation. As Figure 2.4 shows, the supply water goes through the outer pipe and the recirculation water goes through the inner pipe. The in-line supply pipe was designed in accordance with the current product catalogue[12]. The pipe dimensions of the DHW loop range from $35-42 \mathrm{~mm}$, while the diameters of the space heating loop range from $18-28 \mathrm{~mm}$. The heat storage tank is used to provide sufficient hot water during peak load. The tank size was dimensioned by 
considering the domestic hot water peak load, the duration of the peak load, the storage temperature, and the simultaneity factor. The tank was insulated by Class 5 according to the standard [11].

The temperature levels are also crucial inputs for the model. To fulfil the regulations for inhibiting Legionella in domestic hot water systems, the district heating supply temperature to the substation in Scenario 1 was assumed to $70^{\circ} \mathrm{C}$ throughout the year. However, the temperature levels for the space heating loop was assumed to be 35 $/ 25^{\circ} \mathrm{C}$ to provide a comfortable floor surface temperature. In the domestic hot water loop, the temperature of the storage tank was assumed to $60^{\circ} \mathrm{C}$ in accordance with the hygiene standard[4]. The temperature at the outlet of the circulation pipe was assumed to be no less than $55^{\circ} \mathrm{C}$ by thermostatic control.

\subsubsection{Scenario 2. Decentralized substation system with LTDH}

The model of the decentralized substation system was designed to have the same configuration as the case system. The schematic diagram of Scenario 2 is shown in Figure 2.5 . 


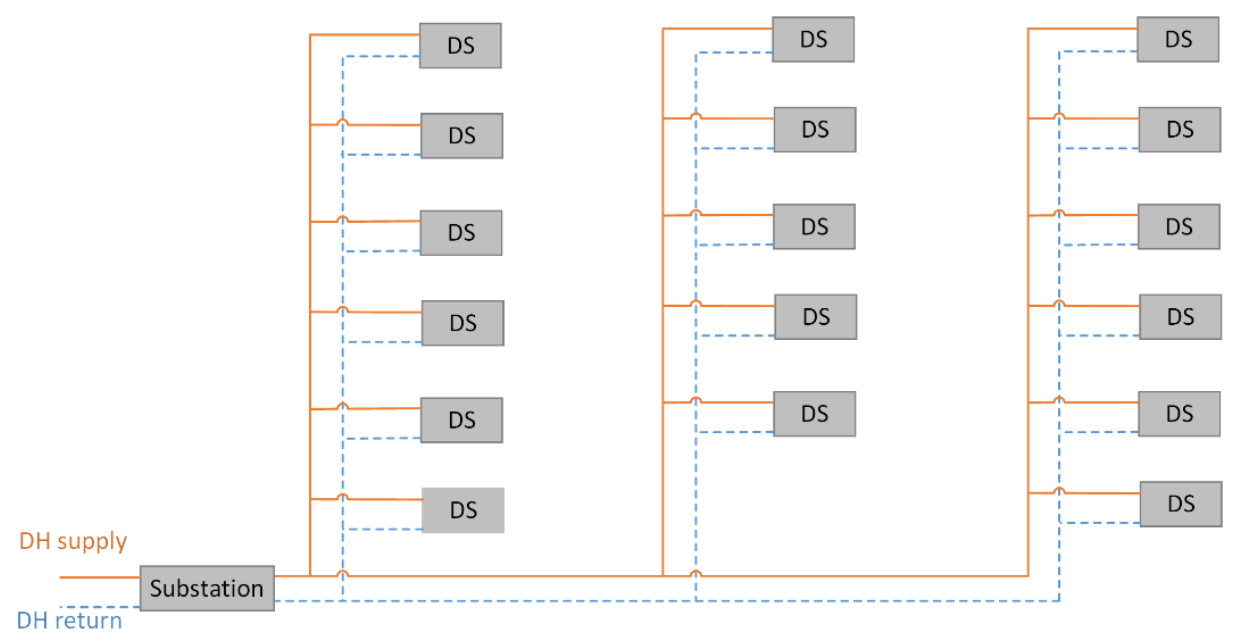

Figure 2.5 Schematic of decentralized substation (DS) system

With the decentralized substation unit, each apartment is decentralized from the centralized heating system. This means that the domestic hot water system inside each flat has a small volume with no circulation. The high-temperature regime to avoid Legionella is not necessary, which gives access to LTDH. According to the design guidelines, the diameter of the pipe line was dimensioned from 33.7-42 mm.

The district heating supply temperature was assumed to $55^{\circ} \mathrm{C}$ for the whole year, so that the supply temperature at the remote decentralized substation unit can be guaranteed to be no lower than $50^{\circ} \mathrm{C}$. The return temperature of the space heating was assumed to $25^{\circ} \mathrm{C}$ based on efficient cooling of floor heating. During the heating season, the space heating is operated all the time to provide comfort indoor temperature. According to the Danish standard [10], the overall tapping period is very limited during a day. So space heating flow dominated the mixed flow in the service pipes. Therefore, the effects of the bypass flow and the flow for domestic hot water were neglected. The 
return temperature of the service pipe was assumed to be the same as the return temperature of space heating.

During the non-heating season, the bathroom floor heating was maintained. Based on Danish Building Regulations 2010 [13], the mass flow for the bathroom floor heating should be sufficient to provide $26^{\circ} \mathrm{C}$ for floor temperature, which was calculated as 19.9 $\mathrm{kg} / \mathrm{h}$ for Scenario 2 . The bypass flow should be sufficient to keep the set-point temperature no less than $50^{\circ} \mathrm{C}$, which was $62 \mathrm{~kg} / \mathrm{h}$. The effect of bypass should be taken into account. The return temperature of the service return pipe was calculated as the weighted average temperature considering both the bathroom heating flow and the bypass flow.

\subsubsection{Scenario 3. Decentralized substation system with in-line supply pipe and heat} pump

A decentralized substation system allows LTDH supply, but the mix with the bypass flow during the non-heating season results in high return temperatures and may restrict the use of LTDH. To reduce the return temperature for the decentralized substation system, an innovative concept was proposed. The idea is to use an in-line supply pipe to keep the supply line warm instead of using the bypass. The operation of the in-line supply pipe was assisted with a heat pump, which aims to cover the heat loss of the supply pipe and maintain the circulation temperature. As a result, the return temperature was expected to be lowered by avoiding mixing with the bypass flow. The dimension of the 
in-line supply pipe was larger than the supply pipe of Scenario2, which ranged from 42$54 \mathrm{~mm}$. The schematic of the new system is shown in Figure 2.6.

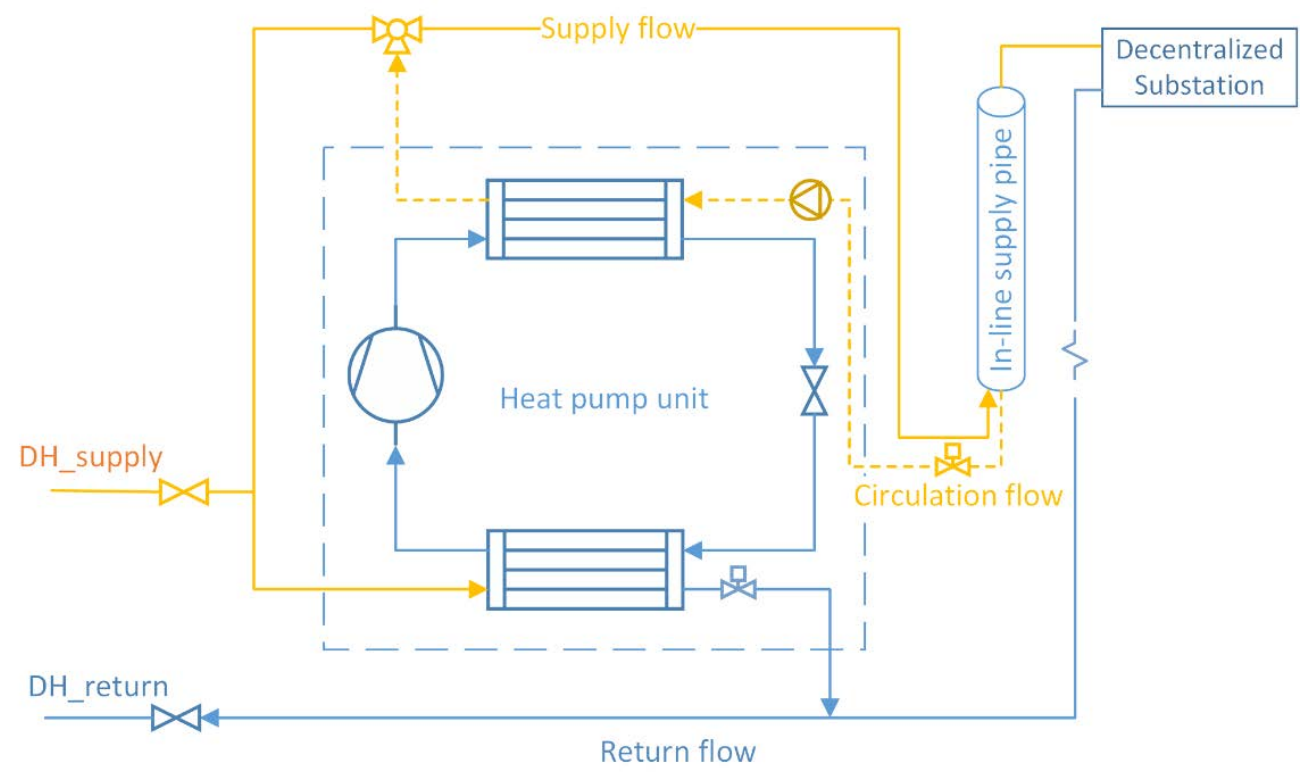

Figure 2.6 Decentralized substation system combined with heat pump and in-line supply pipe

To make sure the consumers can get domestic hot water at a comfort temperature, the temperature of the supply pipe was assumed to be no less than $50^{\circ} \mathrm{C}$. During the nontapping period, the in-line circulation was operated to keep the supply pipe warm. The heat pump was used to transfer heat from the district heating supply to the in-line circulation to compensate for the temperature drop along the in-line supply pipe due to the distribution heat loss. The thermostatic control of the heat pump guaranteed the outlet temperatures of the evaporator to be $25^{\circ} \mathrm{C}$ and the temperature of the in-line circulation no less than $50^{\circ} \mathrm{C}$. Ignoring the impact of domestic hot water draw-off, the heat pump was assumed to work full-time during the non-heating season. In this scenario, the return temperature of the service pipe was assumed to $25^{\circ} \mathrm{C}$ without being mixed with the bypass. 


\subsubsection{Economic analysis}

The costs of covering the distribution heat loss in the three scenarios were calculated and compared. Moreover, the benefit of lower return temperature by applying Scenario 3 was obtained by summing up the cost reduction by the heat loss and savings for the district heating system compared to Scenario 2.

Since Scenario 3 used extra electricity for the heat pump, when calculating the costs of distribution heat loss, different energy prices were considered. For heat loss reduction, the extra cost of Scenario 3 included the heat pump power and the extra heat loss from the enlarged supply pipe. The savings included the reduction in the distribution heat loss of return pipe during the non-heating season. They were calculated as.

$$
\begin{gathered}
C_{\text {sup }}=C_{D H}+C_{e l} \\
C_{e l}=E_{e l} \cdot P_{e l} \\
E_{e l}=Q_{\text {sup }} / C O P \\
C_{D H}=P_{D H} \cdot\left(Q_{\text {sup }}-E_{e l}\right) \\
C_{r e}=P_{D H} \cdot Q_{r e}
\end{gathered}
$$

where,

$C_{\text {sup }}$ is the overall cost of covering the heat loss of the supply line, [DKK]

$C_{e l}$ is the cost of electricity for the heat pump, [DKK]

$C_{D H}$ is the cost of covering the heat loss by district heating, [DKK] 
$E_{e l}$ is the electricity used by the heat pump, [kWh]

$P_{e l}$ is the price for electricity, [DKK/kWh]

$Q_{\text {sup }}$ is the overall heat loss of the in-line supply pipe, [kWh]

COP is the coefficient of performance of the heat pump, the design COP in this case was assumed to 4,

$P_{D H}$ is the price for district heating, [DKK/kWh]

$C_{r e}$ is the cost of covering the heat loss of the return line, [DKK]

$Q_{r e}$ is the heat loss of the return line, [kWh]

The low return temperature can also give benefits for the heat production side, including the decreased pumping power and the option of switching to low-temperature heat sources. According to an investigation in Sweden [14], the estimation of the cost reduction from low return temperature is $1.5 \mathrm{SEK} / \mathrm{MWh} \cdot{ }^{\circ} \mathrm{C}$. Converting to this case, the cost saving ratio was assumed to $1.8 \mathrm{DKK} / \mathrm{MWh} \cdot{ }^{\circ} \mathrm{C}$ considering the different heat prices between Sweden and Denmark.

Thus, the saving by lower return temperatures is:

$$
S=R \cdot Q_{S} \cdot \Delta t_{r e}
$$

where,

$S$ is the cost reduction on the heat production side, [DKK]

$R$ is the cost-saving ratio, here $1.8\left[\mathrm{DKK} / \mathrm{MWh} \cdot{ }^{\circ} \mathrm{C}\right]$ 
$Q_{S}$ is the overall heat supplied to the building when the return temperature is reduced

by heat pump, in this study in the non-heating season, [kWh]

$\Delta t_{r e}$ is the reduction in return temperature, $\left[{ }^{\circ} \mathrm{C}\right]$

The technical parameters for the calculation are shown in Table 2.1

Table 2.1 The technical parameters for the economy analysis

\begin{tabular}{lll}
\hline Features & Abbreviation & Value \\
\hline Price of electricity $[\mathrm{DKK} / \mathrm{kWh}]$ & $\mathrm{P}_{\mathrm{el}}$ & 2 \\
Price of district heating $[\mathrm{DKK} / \mathrm{kWh}]$ & $\mathrm{P}_{\mathrm{DH}}$ & 0.8 \\
Heat pump COP & $\mathrm{COP}$ & 4 \\
Cost-saving ratio of low return temperature $\left[\mathrm{DKK} / \mathrm{MWh}^{\circ} \mathrm{C}\right]$ & $\mathrm{R}$ & 1.8 \\
\hline
\end{tabular}

\section{Results}

\subsection{Measurements and simulation results for the case heating system}

To test the average return temperature during the non-heating season, the two-day test

was performed on $28^{\text {th }}$ August $-29^{\text {th }}$ August, 2014. The simulated result of the weighted average return temperature was $43.9^{\circ} \mathrm{C}$ by the model. The deviation between the measurements and the calculation result is shown in Figure 3.1 


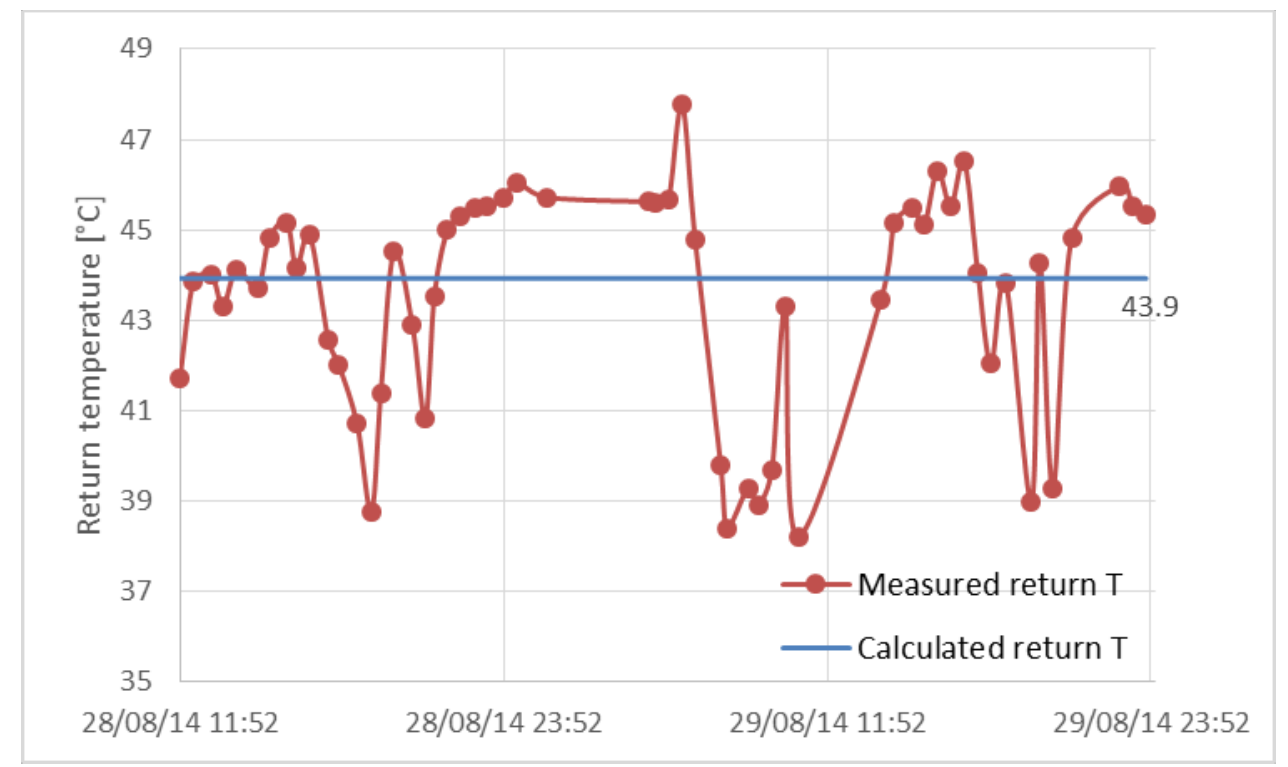

Figure 3.1 Deviation between the measured return temperature and calculated return temperature

The measured return temperatures fluctuate around the calculated value. The average deviation is $2.44{ }^{\circ} \mathrm{C}(\chi=-0.39)$. Several data points have obvious negative deviations. That is mainly caused by peak load of domestic hot water. During the tapping period, the return temperature of domestic hot water is lower than the bypass temperature, which made the average return temperature lower than the estimation. The drops match the load profile of domestic hot water in the case building and are also consistent with our assumption that tapping occurred for very limited lengths of time during the test period. The effect on the average return temperature is negligible.

By inputting the measured instantaneous temperature into the model, it was possible to calculate the heat loss rates of the supply line and return line of the decentralized substation system, as well as the accumulated heat loss. The measured distribution heat loss was compared with the simulated values. The results are shown in Figure 3.2 (a) and (b) respectively. 


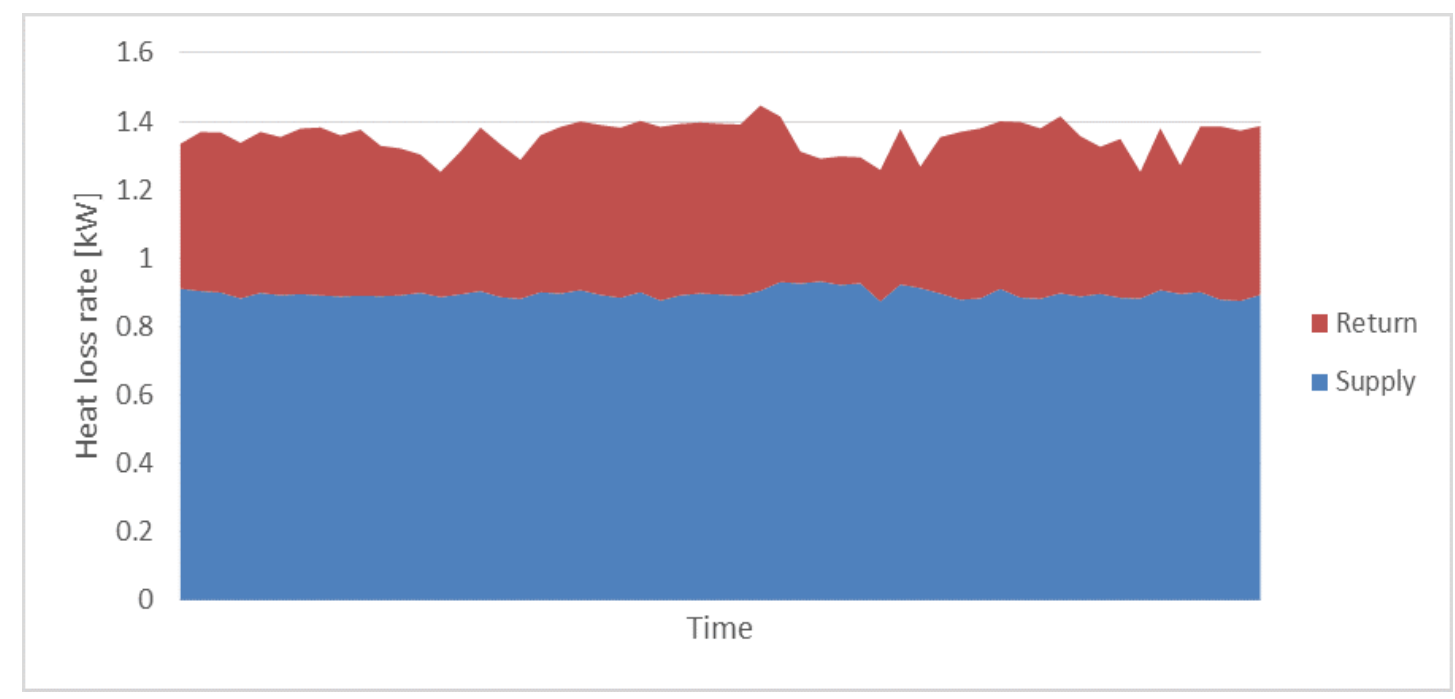

(a)

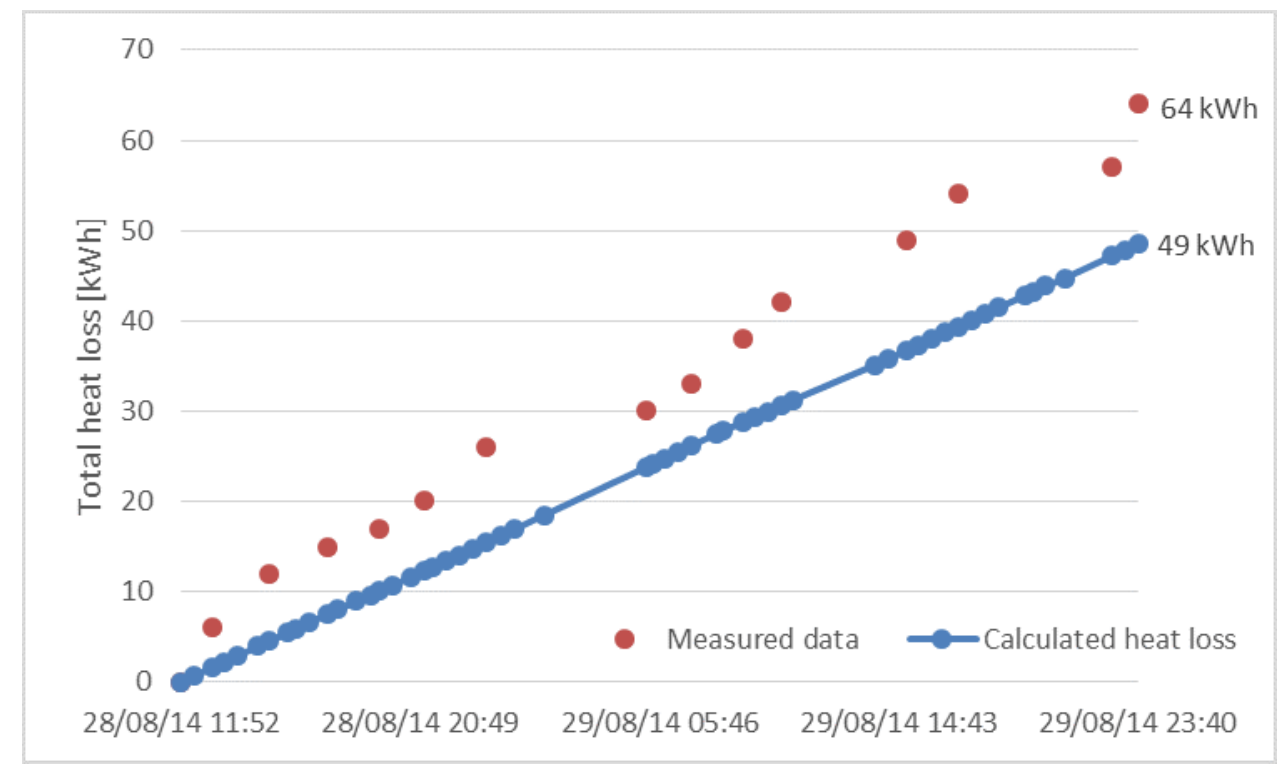

(b)

Figure 3.2 Simulation results of the heat loss rate (a) and accumulated heat loss (b)

In Figure 3.2 (a), the blue area represents the heat loss rate of the supply line, and the red area above represents the heat loss rate of the return line. The heat loss rate of the supply line is stable, while the return line has more fluctuations. That is the result of the tapping load. According to the measurements, the accumulated heat loss at the end of the test period achieved $64 \mathrm{kWh}$, while the simulated result was $49 \mathrm{kWh}$. The deviation 
of $23 \%$ can be explained by the fact that the model was built based on ideal conditions, which did not include the effects of thermal bridges, such as pipe junctions or contact with the surrounding walls in reality. However, it is possible to eliminate the extra heat loss in the future by more precise system design and construction. For the following scenario analysis, all three models were built under ideal conditions to make fair comparisons.

\subsection{Distribution heat loss of the three scenarios}

All three scenarios were modelled with the input parameters defined in the previous section. The input temperature of the ideal model was changed to simulate the system performance with LTDH supply. Separate results are given for the heating and nonheating seasons, as shown in Table 31.

Table 3. 1 Distribution heat loss for the three scenarios [kWh]

\begin{tabular}{llrrrr}
\hline & & \multicolumn{2}{c}{ Scenario 1 } & & \\
\cline { 2 - 5 } & & $\begin{array}{c}\text { Space heating } \\
\text { loop }\end{array}$ & $\begin{array}{c}\text { Domestic hot } \\
\text { water loop }\end{array}$ & Scenario 2 & Scenario 3 \\
\hline Heating season & supply & 1230 & 3952 & 2978 & 3233 \\
& return & 406 & - & 496 & 496 \\
Non-heating season & supply & 884 & 2852 & 2149 & 2333 \\
& return & 293 & - & 1714 & 358 \\
Tank & & & 840 & - & - \\
Annual & & & 10457 & 7337 & 6420 \\
Heat loss savings & & & $0 \%$ & $30 \%$ & $39 \%$ \\
Compared to Scenario 1 & & & & & \\
\hline
\end{tabular}

The conventional system has the largest distribution heat loss, followed by decentralized substation system with LTDH, while the decentralized substation system 
with LTDH and the in-line supply pipe and heat pump has the lowest distribution heat loss of all the scenarios.

Compared with Scenario 1, Scenario 2 can save $30 \%$ of the annual distribution heat loss and Scenario 3 can save 39\%. The domestic hot water loop of Scenario 1 requires high temperature regime and circulation to inhibit Legionella. Furthermore, the extra pipe work with separate space heating loops and domestic hot water loops also results in large heat loss.

\subsection{Distribution costs of the three scenarios}

The costs of covering the distribution heat loss for the three scenarios were calculated to evaluate the economics of the heat distribution process. The annual costs for the supply line and return line were calculated separately. The results are shown in Table

\section{2.}

Table 3.2 The cost of covering the distribution heat loss for the three scenarios

\begin{tabular}{|c|c|c|c|c|}
\hline Costs & Scenario 1 & Scenario 2 & \multicolumn{2}{|c|}{ Scenario 3} \\
\hline \multirow{2}{*}{ Cost of supply line } & \multirow{2}{*}{7807} & \multirow{2}{*}{4101} & Heat & Electricity \\
\hline & & & 3987 & 700 \\
\hline Cost of return line & 599 & 1768 & \multicolumn{2}{|c|}{683} \\
\hline $\begin{array}{l}\text { Total annual cost caused by the } \\
\text { distribution heat loss[DKK/yr] }\end{array}$ & 8366 & 5869 & \multicolumn{2}{|c|}{5370} \\
\hline
\end{tabular}

The conventional system has the highest cost for covering the distribution heat loss.

Because of the cost of electricity consumed by the heat pump and the larger pipe dimensions of the in-line supply pipe, Scenario 3 incurs 586 DKK more on covering the distribution heat loss of the supply line than Scenario 2. However, the lower return 
temperature of Scenario 3 during the non-heating season leads to 1084 DKK cost

reduction of the return line compared to Scenario 2. Moreover, supplying the same heat demand as the case building, Scenario 3 can save 577 DKK for district heating system compared with Scenario 2. Therefore, comparing the total economy of the low return temperature, Scenario 3 can save $18 \%$ on the operation cost compared to Scenario 2 . In practice, the COP of the heat pump depends on the actual inlet/outlet temperatures, a more realistic value might be around 3.5. The actual electricity consumed by the heat pump could be more than the design case, which can lead to less cost reduction. But, the cost-saving ratio of $1.8 \mathrm{DKK} / \mathrm{MWh}^{\circ} \mathrm{C}$ is an average value; if the heat source is strongly temperature-dependent, the cost-saving ratio could be higher, which means more savings for the district heating system.

\section{Discussion}

\subsection{Energy-saving effect of the decentralized substation system}

To fulfil hygiene and comfort requirements, the most common approach to supply heat to multi-storey buildings is domestic hot water circulation with a high-temperature regime. However, this approach leads to unnecessary distribution heat loss and reduces the energy efficiency of the entire system.

Scenario 2 and Scenario 3 implemented decentralized substation units. In contrast to the centralized heating system, the decentralized substation system can balance the conflict between the hygiene requirements and energy efficiency. Domestic hot water 
circulation at high temperature is no longer necessary to inhibit Legionella in the decentralized substation system. For energy-efficient buildings in the future, LTDH supply with efficient space-heating devices will be sufficient to provide comfort indoor temperatures for consumers. This makes the system of decentralized substations a promising solution for the realization of LTDH in multi-storey buildings. The benefits include not only savings in distribution heat loss, but also access to more low-quality energy sources that might have lower energy prices. Moreover, the decentralized substation system without storage tanks and circulation pipes has simpler layout than the conventional system. However, in view of the investment costs, the decentralized substation system is best applied in new constructions. During the transition period, the decentralized substation system with medium-temperature district heating can be considered as preparation for realizing LTDH.

\subsection{Seasonal variation}

The heating demand varies in different seasons. To adapt to the decreased heating demand in the summer, the supply temperature of district heating normally is reduced. However, the decreased heating demand means the district heating return flow cannot have efficient cooling, which leads to high return temperature. Figure 4.1 shows the measurements of supply/return temperature in the case building for a whole year. 


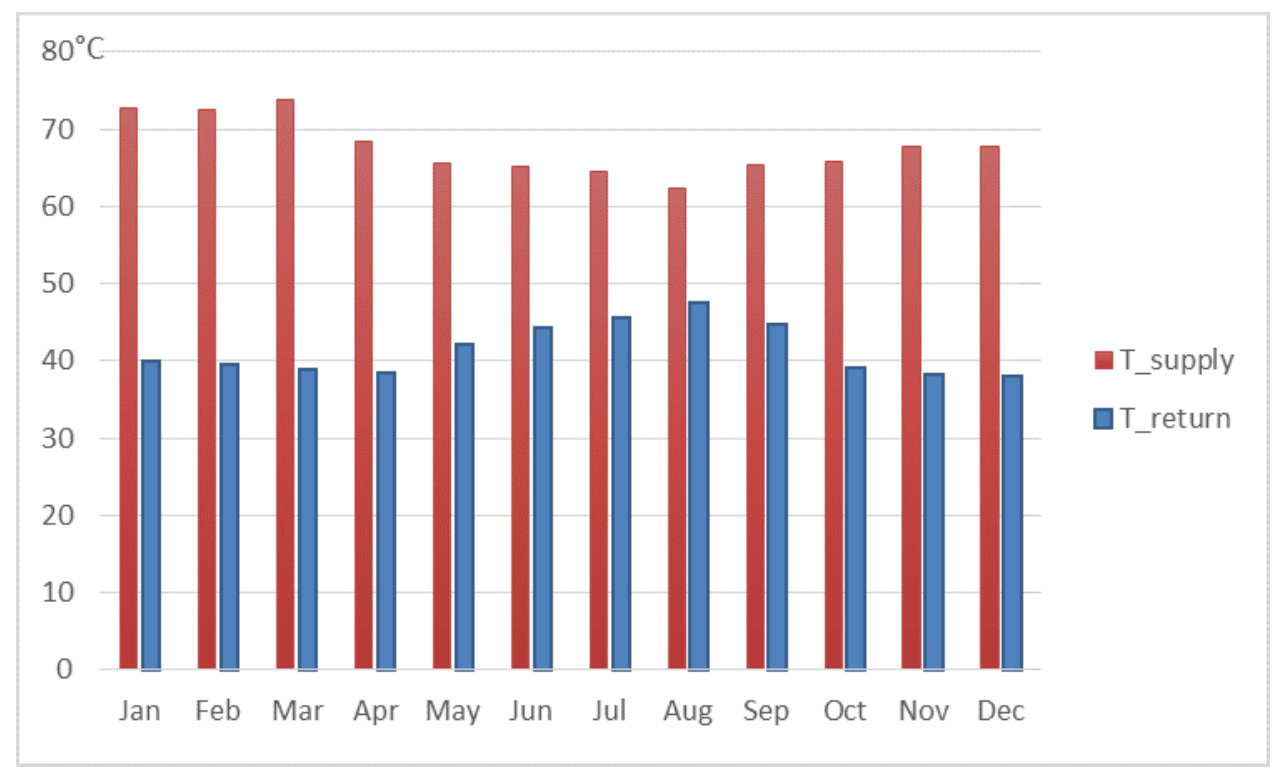

Figure 4.1 Measured supply and return temperatures in the case building

The return temperature to district heating shows different trend from the district

heating supply temperature. The return temperature reaches a small peak during the non-heating season. Besides the inefficient cooling, the mix of bypass flow also contributes to the temperature increase of the return flow. And that undoubtedly leads to higher heat loss.

According to the model calculation, Figure 4.2 shows the comparison of the seasonal heat loss of the three scenarios for the return line. 


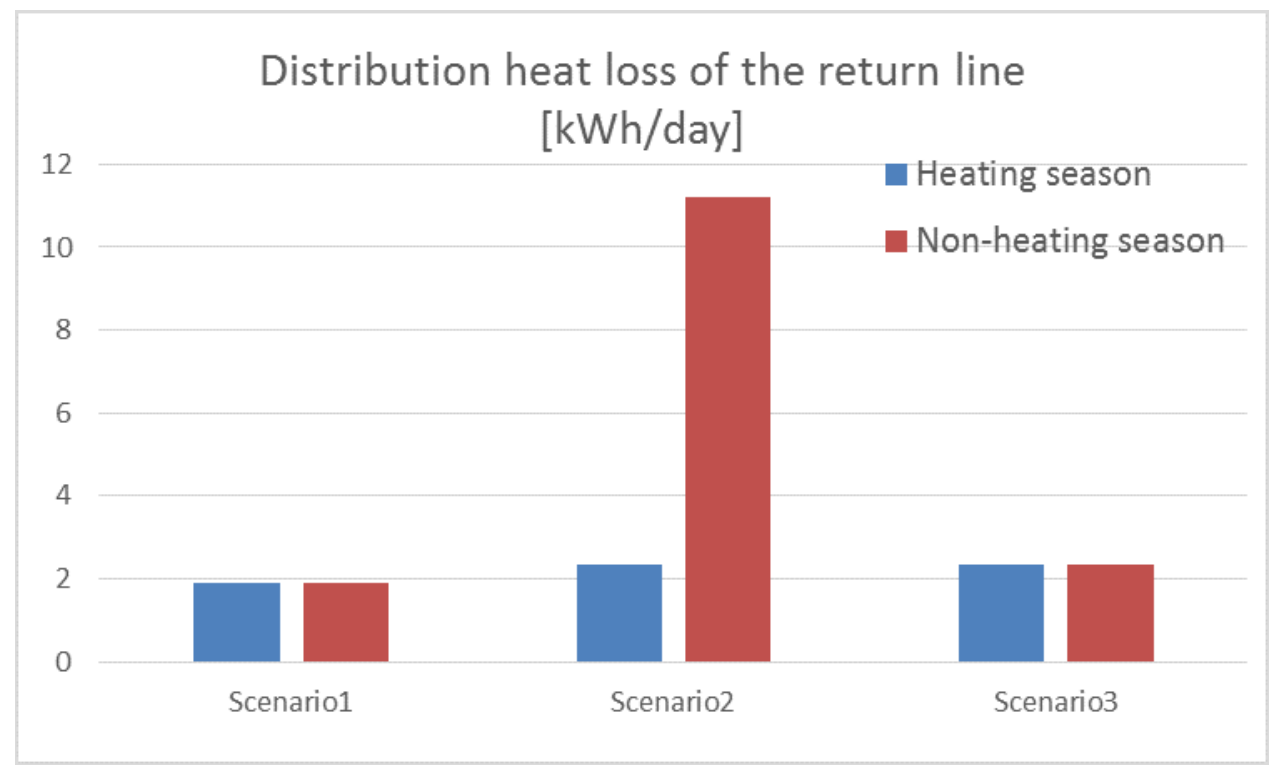

Figure 4.2 Seasonal variation of the distribution heat loss of the return pipelines

The three scenarios have similar distribution heat loss of the return lines in the heating season. However, during the non-heating season, Scenario 2 shows a significantly higher distribution heat loss on the return line than the other two scenarios. In the case building with decentralized substation system, the annual heat loss percentage was approximately $10 \%$ of the total heat delivered, while the percentage in summer was almost $30 \%$. The high return temperature during the non-heating season plays a role in the high heat loss. As the application to realize LTDH in the future, such high return temperature will no doubt restrict the overall energy efficiency of the decentralized substation system. Therefore, methods should be considered to reduce the average return temperature of the decentralized substation system without violating the comfort requirement. 


\subsection{Reducing the return temperature for LTDH}

A high return temperature is a long-term problem that restricts the efficiency of the distribution process. Moreover, the return temperature can deeply affect the heat production process too, depending on the type of heat source used. For example, if the district heating is supplied by excess heat from industrial processes, lower return temperatures help increase the heat recovery efficiency of the excess heat source or the efficiency of the turbine. And lower return temperatures make it more feasible and promising to apply low supply temperatures. As a result, more heat sources with low energy quality can be applied, and fossil fuels can be replaced as the backup heat source for peak loads.

One benefit of using the decentralized substation system is that such systems can use LTDH without risk of Legionella. However, the use of the high-temperature bypass flow restricts the lower limit of the return temperature. In Scenario 2, the bathroom heating during the non-heating season helps reduce the average return temperature to some extent, but it is not sufficient enough to replace the bypass flow completely. In Scenario 3, lower return temperature was obtained by using a combination of in-line supply pipe and heat pump to replace the bypass function. According to the results of this study, even though the supply pipe has larger dimensions and extra electricity is consumed for the heat pump, Scenario 3 still has the lowest cost for covering the distribution heat loss. Moreover, the low return temperature also gives benefits to the heat production side and the district heating network. However, the exact economic benefits of the low 
return temperature can only be evaluated for specific cases with concrete information on the heat source type, the pipework of the network, the investment in applied devices, etc.

\section{Conclusion}

This study investigated the energy and economy performances of the decentralized substation system with LTDH supply. Models of conventional system with medium temperature district heating, decentralized substation system with LTDH, and innovative decentralized substation system with LTDH supply were built to make scenario analysis. The results obtained by comparing the three systems can be summarized as follows:

- The decentralized substation system can be operated with LTDH $\left(55^{\circ} \mathrm{C}\right)$ without risk of Legionella. It is a promising solution for energy-efficient buildings with a large domestic hot water heating system.

- Although the space-heating loops of the conventional system were designed to be operated efficiently with floor heating, the extra pipelines with separate space heating and domestic hot water loops, as well as the high-temperature regime to prevent Legionella still lead to high overall distribution heat loss.

- The decentralized substation system with LTDH can save $30 \%$ of the annual distribution heat loss compared to the conventional system.

- Replacing the bypass function with an in-line supply pipe and a heat pump can help to reduce the return temperature of the decentralized substation system. As a result, the annual distribution heat loss decreased by $12 \%$. Also by 
considering the potential savings for the district heating system, the innovation

decentralized substation system can help to save 577DKK by the operation in

non-heating season.

Finally, this study provides the basis for a future full-scale analysis of a decentralized substation system with improved lower return temperatures.

\section{Acknowledgement}

The work presented in this paper is a result of the research activities of the Strategic

Research Centre for 4th Generation District Heating (4DH), which has received funding

from the Innovation Fund Denmark.

\section{References}

[1] Lund H, Werner S, Wiltshire R, Svendsen S, Thorsen JE, Hvelplund F, et al. 4th Generation District Heating $(4 \mathrm{GDH})$ Integrating smart thermal grids into future sustainable energy systems. Energy. 2014;68:1-11.

[2] Brand M, Svendsen S. Renewable-based low-temperature district heating for existing buildings in various stages of refurbishment. Energy. 2013;62(0):311-9.

[3] Bøhm B. Production and distribution of domestic hot water in selected Danish apartment buildings and institutions. Analysis of consumption, energy efficiency and the significance for energy design requirements of buildings. Energy Conversion and Management. 2013;67.

[4] DS/CEN/TR16355. Recommendations for prevention of Legionella growth in installations inside buildings conveying water for human consumption. København: CEN; 2012.

[5] Breuer W, Loose P. Energy conservation and domestic hot water consumption with decentralised district heating connections for individual dwellings. Fuel and Energy Abstracts. 1997;38(4).

[6] Cholewa T, Siuta-Olcha A. Experimental investigations of a decentralized system for heating and hot water generation in a residential building. Energ Buildings. 2010;42(2):183-8.

[7] Cholewa T, Siuta-Olcha A, Skwarczyński MA. Experimental evaluation of three heating systems commonly used in the residential sector. Energ Buildings. 2011;43(9):2140-4.

[8] Thorsen JE. Analysis on flat station concept. The 12th international symposium on district heating and cooling. Tallinn, Estonia2010.

[9] SBI. Building for commercial and apartment blocks 1995 (BR95). Copenhagen, Denmark1996.

[10] DS439. Code of Practice for domestic water supply installations. København2009.

[11] DS452. Termisk isolering af tekniske installationer. Charlottenlund: Dansk Standard; 2013.

[12] Viega. Smartloop Inliner system Profipress med 12 mm PB rør. 
[13] Building Regulations 2010 Copenhagen: The Danish Ministry of Economic and Business Affairs.

Danish Enterprise and Construction Authority.; 2010.

[14] Svend F, Sven W. District heating and cooling. first ed. Sweden: Studentlitteratur, 2013. 